\title{
0 "direito à cidade" enquanto categoria em disputa: uma análise dos conflitos políticos em torno dos usos cotidianos da Praça Roosevelt, em São Paulo
}

André de Pieri Pimentel ${ }^{1}$

\section{Resumo}

As cidades contemporâneas são palco de uma pluralidade de conflitos em torno dos usos de espaços públicos e também de suas regulações. Enquanto agentes e grupos políticos se mobilizam em prol do recrudescimento da distinção entre usos autorizados e usos não permitidos desses espaços, através da presença de policiais, tecnologias de vigilância e até mesmo da formulação de leis, outros se posicionam em defesa do "direito à cidade", contra o policiamento ostensivo e a criminalização da livre apropriação dos espaços públicos. Esse artigo propõe reflexão baseada em pesquisa etnográfica realizada na praça Franklin Roosevelt, no bairro da Consolação (região central de São Paulo). Nos últimos anos, após uma reforma multimilionária que a transformou completamente, sob o pretexto de produzir "requalificação urbana", diferentes projetos de gestão e mesmo de ocupação se fizeram presentes nesse espaço, estabelecendo alianças e relações conflitivas uns com os outros. Em meio à produção de ordenamentos urbanos divergentes, os usuários cotidianos da praça estabelecem extensões, tensões, rupturas e resistências a tais projetos ordenadores. A praça Roosevelt contemporânea é um território disputado, e essas disputas desvelam projetos políticos e projetos de cidade em uma dimensão mais ampla. 0 objetivo desse artigo é reconstituir alguns desses conflitos atuais, identificando os agentes coletivos que se constituem em torno deles, os discursos políticos e as redes pessoais ou institucionais que eles mobilizam em suas atuações.

\section{Palavras-chave}

Praça Roosevelt (São Paulo); Gestão urbana; Direito à cidade.

\begin{abstract}
Contemporary cities are the scenario of many conflicts regarding the use and management of public spaces. While political agents and groups stand in favor of a distinction reinforcement between authorized and unauthorized uses of these spaces, through the presence of police, surveillance technologies and even the formulation of laws, others stand in defense of the "right to the city", against ostensive policing and the criminalization of free appropriation of public
\end{abstract}

${ }^{1}$ Doutorando em Ciências Sociais na Unicamp. E-mail: andre.pierip@gmail.com. 
spaces. This article proposes a reflection based on ethnographic research carried out in Franklin Roosevelt Square, in the Consolação neighborhood (central region of São Paulo, Brazil). In recent years, after a multimillionaire reform that transformed it completely, under the pretext of creating "urban requalification", different management and occupation projects were present in this space, establishing alliances and conflicts with each other. Amid the creation of divergent urban orders, the daily users of the square establish extensions, tensions, ruptures and resistance to these ordering projects. The contemporary Roosevelt Square is a disputed territory, and these disputes unveil political projects and city projects in a broader dimension. This article proposes a reconstruction of these current conflicts, identifying the collective agents that are built around them, the political discourses and the personal or institutional networks that they mobilize with their actions.

\section{Keywords}

Roosevelt Square (São Paulo). Urban Management. Right to the City.

Esse artigo expõe resultados de pesquisa etnográfica realizada na Praça Franklin Roosevelt, no bairro da Consolação (região central de São Paulo)2 Construída em 1970, em meio ao regime militar, a praça foi reformada no ano de 2010 - obra que teve o custo total de R\$ 55 milhões. Dentre as intenções de tal intervenção multimilionária, que contou inclusive com a mobilização de recursos oriundos de agências financiadoras internacionais, existia a tentativa de um maior controle estatal dos usos daquele espaço, administrando possibilidades e reprimindo usos considerados impróprios. Porém, apesar da intensa presença e circulação das forças policiais no local após a reforma, e de um processo de enobrecimento que vem sendo presenciado em seus arredores ${ }^{3}$, não apenas algumas modalidades de "usos insurgentes" (PEREIRA, 2017) ainda se fazem presentes ali como muitas delas acabam assumindo uma

\footnotetext{
${ }^{2}$ A pesquisa que serve de base para esse artigo é minha pesquisa de mestrado, defendida em 2018 junto ao Programa de Pós-Graduação em Sociologia da Universidade Federal de São Carlos. Foi orientada pelo prof. Dr. Gabriel Feltran, a quem agradeço pelas gentis contribuições. Deixo registrados também meus agradecimentos à FAPESP, por financiar a realização dessa pesquisa através de bolsa mestrado (processo ${ }^{\circ}$ 2016/05431-8). Fiz visitas regulares à praça Roosevelt entre agosto de 2016 e outubro de 2017. Além do material etnográfico produzido nesse período, realizei entrevistas e compilei diversos tipos de material secundário (matérias jornalísticas, textos publicados na internet, textos de Leis, Projetos de Lei ou Decretos municipais, documentos de interesse e vídeos de intervenções poéticas filmados no local, entre outros).

${ }^{3}$ Depois da reforma da praça, é notável o aumento da presença de estabelecimentos comerciais elitizados, como bares, casas noturnas, restaurantes e tabacarias. Além disso, presenciou-se uma grande valorização dos imóveis na região.
} 
configuração mais diretamente crítica com relação à restrição de usos e de apropriações dos espaços públicos na cidade.

O objetivo desse artigo é analisar interfaces entre certos mecanismos de gestão desse espaço e as suas apropriações práticas. Propõe-se que o plano do cotidiano (CERTEAU, 2009) seja tomado como plano privilegiado de observação etnográfica. Ao partir de apropriações cotidianas de um espaço público em específico, intento fugir de leituras reificadas e normativas do conceito de "espaços públicos". Intento analisar como esse espaço se produz enquanto público em uma dimensão prática, na medida em que é apropriado e mobilizado enquanto arena de veiculação de projetos e de discursos sobre a cidade de forma mais geral. A cidade aqui, portanto, é tomada não como unidade (ou totalidade) territorial, mas sim como categoria em dissenso, que mobiliza representações políticas e projetos gestionários divergentes.

Nos espaços públicos, tais representações sobre a cidade são performadas e contrapostas por uma pluralidade de agentes, redes e instituições, políticas ou gestionárias. Elas emergem em meio a suas apropriações cotidianas por parte dos citadinos. Na medida que tais usos desvelam sentidos diferentes para a categoria "cidade", sua emergência nos espaços públicos atua como elemento estabelecedor de uma partilha do sensível (RANCIÉRE, 2005). Longe de produzir harmonia e tolerância, a convivência entre as diferenças nos espaços públicos produz dissensos, rupturas e ruídos (RANCIÉRE, 1996). Esses dissensos fazem cidades em uma dimensão concreta (AGIER, 2011, 2015), e podem ser vistos como um interessante mote para uma análise sobre a produção da cidade enquanto categoria política, que evoca e mobiliza alteridades em múltiplos níveis - do plano discursivo ao plano do sensível e do inteligível. Essas diferentes formas de pensar (e de fazer) a cidade influenciam a formação de grupos e de redes políticas, que possuem estratégias distintas de atuação e diferentes tipos e graus de interface com o poder público.

Pensar a cidade enquanto categoria política implica em um duplo movimento. Por um lado, envolve uma análise da produção histórica de ordenamentos urbanos, estatais e não estatais, ${ }^{4}$ enquanto mecanismos de classificação e de regulação de populações, de territórios e de fluxos. Por outro lado, envolve também uma análise das apropriações práticas desses territórios regulados, e de que forma os citadinos transitam entre usos insurgentes e

\footnotetext{
${ }^{4}$ Aqui me baseio nas contribuições de Feltran $(2012,2014)$ sobre a produção de ordenamentos urbanos a partir de regimes normativos diferentes do regime estatal, e também de Das e Poole (2008) sobre as margens do estado enquanto esferas relevantes da gestão estatal de populações e territórios.
} 
resistências politizadas. Mais do que a simples distinção entre apropriações permitidas e não permitidas, me interessa analisar de que forma esses usos considerados não permitidos produzem dissensos políticos, entre aqueles que defendem sua criminalização e aqueles que os veem como formas legítimas de apropriação do urbano. Essa distinção entre usos insurgentes e resistências politizadas não se refere apenas a diferenças entre formas de apropriação dos espaços públicos, ela é um processo relacional, que mobiliza e também tensiona projetos políticos e projetos de cidade distintos. A construção política das formas de se categorizar os usos possíveis de espaços urbanos envolve a produção relacional de criminalização de determinadas modalidades, e não simplesmente o estabelecimento de uma distinção entre apropriações permitidas e não permitidas.

Em uma dimensão teórico/metodológica, esse artigo dialoga com as reflexões de Henri Lefébvre sobre a produção do espaço (1991) e sobre o "direito à cidade" (2001). Há também um diálogo com a reflexão foucaultiana sobre os aspectos produtivos e sobre os efeitos capilares da atuação de dispositivos ordenadores do social (FOUCAULT, 1987, 1988, 2005, 2009). Ambos esses referenciais teóricos são importantes para a produção de uma "sociologia urbana do poder" (HIRATA, 2018). Ao mesmo tempo, há um diálogo com uma discussão mais situada no campo da antropologia, conduzido por autores que propõem uma "antropologia das cidades" (AGIER, 2011; FRÚGOLI JR, SPAGGIARI E ADERALDO, 2019; MAGNANI, 2002). Alçando a cidade ao status de objeto do conhecimento, e não mais de um pressuposto teórico ou de um recorte territorial delimitado, propõe-se o questionamento de definições normativas sobre as cidades, e acima de tudo, propõe-se a centralidade da pesquisa etnográfica para a construção desse objeto em aberto.

Muitas vezes a temática das cidades nas Ciências Sociais foi tratada com base na ideia de "progresso", seja ele cultural/moral (PARK E BURGESS, 1984) ou material/econômico (CASTELLS, 1972; LEFÉBVRE, 1991). No contexto contemporâneo, presenciamos tanto deslocamentos nos vínculos históricos entre a cidade e a acumulação do capital (HARVEY, 1992; SASSEN, 2007) quanto a emergência de reflexões que buscam pensar especificidades da produção das cidades no "sul global" (ROY, 2017) e na América Latina (GORELICK, 2005). Ao mesmo tempo que a cidade enquanto problema público de certa forma remete a questões globais, como a "gentrificação", o policiamento dos espaços públicos e a realização de intervenções urbanas, ela também mobiliza configurações específicas em São Paulo, uma cidade na periferia do capitalismo (FURTADO, 2009), cujo desenvolvimento histórico 
produziu um tecido urbano territorialmente segregado e socialmente desigual (KOWARICK, 1979).

Na bibliografia produzida sobre a cidade de São Paulo, elementos interessantes permitem pensar articulações históricas entre a produção da cidade enquanto problemática global, associada a um certo "projeto civilizatório" (de populações e também de territórios vistos como "pouco desenvolvidos") e a cidade enquanto dispositivo de produção de uma segregação territorializada das classes pobres. A própria história do centro de São Paulo, em certo sentido, é uma história da construção de técnicas urbanísticas de produção de segregação sócio-espacial dos pobres, sobretudo dos pretos. Para que a região fosse mantida como exclusiva para as elites brancas, foi produzida uma rígida legislação urbanística para regular as edificações, a habitação e até mesmo os usos possíveis desses espaços, isso ainda no século XX (ROLNIK, 1997).

Já nos anos 1970 e 1980, o centro de São Paulo não figurava mais como uma "centralidade econômica" na cidade (FRÚGOLI JR., 2000). Agora ele assumia a configuração de uma região ainda de importante atividade econômica, mas marcadamente popular (KARA JOSÉ, 2010). Em meio à emergência de uma narrativa sobre o crescimento do medo e da insegurança e sobre o "fim da vida pública", o centro de São Paulo passava a ser visto como região "degradada" (CALDEIRA, 2000). Ao mesmo tempo, as periferias urbanas se expandem e emergem como problema público, sobretudo a partir da atuação dos chamados "novos movimentos sociais" (PAOLI, 1995). Em um primeiro momento, o "problema" das periferias era visto através da ótica da redemocratização política, projeto ainda em construção nesse contexto. Curiosamente, depois da redemocratização do aparato estatal brasileiro, não apenas esses mesmos movimentos sociais periféricos enfrentaram uma despolitização de sua atuação como as próprias periferias urbanas passariam a ser vistas a partir de um outro paradigma, o da violência e do crime (FELTRAN, 2010). De símbolo da esperança por democracia, as periferias passariam a ser vistas como exemplo concreto dos limites da redemocratização.

Essa oposição entre o "centro" e a "periferia", tão recorrente no campo dos estudos urbanos, não se produz de forma rígida ou estanque. A produção prática dessa oposição envolve elementos geográficos, políticos, estéticos, simbólicos e até mesmo epistemológicos. E esse processo produz tensões justamente porque se produz a partir de clivagens e de fluxos. A produção de fronteiras urbanas, tal como argumenta Feltran (2011), não mobiliza apenas alteridades, rupturas e cisões, mas mobiliza também interfaces - e interfaces 
reguladas. Elas não se referem apenas a fronteiras entre territórios urbanos, mas sim também à produção de alteridades e de mediações sociais. A produção de fronteiras entre formas de apropriação da cidade produz também fronteiras entre citadinos e entre formas de se fazer cidades.

\title{
A construção política da reforma da praça Roosevelt (2010-2012)
}

\begin{abstract}
“Uma cidade mais humana - Pela audácia de sua concepção arquitetônica, a praça Roosevelt é um resumo da nova São Paulo. Uma praça de quatro andares, única no mundo, como única no mundo é a metrópole paulista. Em São Paulo, o futuro foi antecipado pelas obras, que conseguiram o milagre de engrandecê-la e torná-la mais humana, porque foram feitas com vistas voltadas para o homem" 5 .
\end{abstract}

“Pode ter sido mera coincidência, mas quando no final dos anos 60 transformaram a praça Roosevelt em um amontoado de concreto e na passagem subterrânea de uma via expressa interligando a zona leste a oeste, começou a desaparecer também o circuito cultural que a cidade nunca mais conseguiu estabelecer.

A agitação cultural do centro cedeu lugar à sujeira deixada pelos camelôs e à violência dos meninos de rua, embalados na loucura das drogas e sempre à espreita de sua próxima vítima"6.

A estrutura concretada da praça Roosevelt foi construída no ano de 1970, em grande medida motivada pela edificação de uma obra voltada à circulação rodoviária - o "Minhocão" (Elevado Costa e Silva7), viaduto inaugurado no ano seguinte, que fazia a ligação entre as regiões leste e oeste de São Paulo. Antes disso, ainda nos anos 1950, a então chamada "praça da Consolação" já era um lugar apropriado por uma pluralidade de usos e de sociabilidades. $\mathrm{Na}$ época, seu espaço tinha a topografia de um grande calçadão, que aos dias e durante as semanas servia como estacionamento de carros. Às noites, a praça

\footnotetext{
${ }^{5}$ Excerto de matéria publicada pela revista Manchete em 1969, durante as obras de construção da Praça Roosevelt. Disponível em Palma (2010, p. 143).

${ }^{6}$ Excerto do livro Noites Paulistanas, do jornalista Hélvio Borelli (publicado em contexto posterior à construção da Praça Roosevelt). Disponível em Palma (2010, p. 136).

${ }^{7}$ No ano de 2016, durante a gestão de Fernando Haddad (PT) na prefeitura de São Paulo, foi aprovado pela Câmara Municipal projeto de lei que alterou o nome oficial do "Minhocão" para Elevado Presidente João Goulart. Depois de uma longa controvérsia em torno do "destino" do Elevado, a gestão municipal sinaliza transformá-lo em um parque público, e o fechamento para o tráfego de automóveis.
} 
era apropriada pelo público frequentador dos bares, restaurantes, casas noturnas e salas de teatro localizados nos entornos e nos arredores. Um público elitizado, composto por boêmios, artistas, estudantes universitários, eventualmente celebridades nacionais ou internacionais. Aos fins de semana, aquele espaço abrigava uma feira, além de atividades esportivas e de lazer (PALMA, 2010).

A praça da Consolação era um importante pedaço ${ }^{8}$ cultural em São Paulo nesse contexto, em que a região central de São Paulo ainda era muito apropriada pelas elites. Já a construção da estrutura concretada da praça Roosevelt, em 1970, se situa em um momento posterior, onde presencia-se o avanço desse processo de "popularização" do centro. Nos planos originais, a praça fora concebida como uma "praça-edifício", espaço provido de áreas destinadas ao lazer e à oferta de serviços. Inspirada na arquitetura modernista, e também em um certo ideal desenvolvimentista bastante mobilizado durante a ditadura militar, a praça era composta de seis pavimentos, compostos de curvas e formas pontiagudas, em níveis topográficos distintos e conectados por escadarias. Grandiosa e tecnicamente complexa, a nova praça simbolizaria uma "nova São Paulo", moderna e ao mesmo tempo humana.

Mas, pouco tempo depois de inaugurada, a praça já apresentava problemas estruturais, um baixíssimo grau de manutenção e, além disso, já era majoritariamente apropriada por "tipos marginais", como moradores de rua e usuários de drogas. A presença dessas pessoas era considerada uma forma de "uso insurgente" do espaço, que contribuiria diretamente para sua deterioração física. Essa classificação de determinadas formas de uso de espaços públicos como "insurgentes" muitas vezes se refere mais a clivagens entre agentes do que entre formas de apropriação em si. Em meio à ascensão de narrativas que apontavam a "degradação" do centro de São Paulo, a praça Roosevelt era um símbolo materializado desse processo - e pior, bem debaixo dos narizes das elites. Nesse contexto, parece um consenso compartilhado por todos que aquela praça era um "erro urbanístico", e que para melhorar a qualidade urbana daquele espaço era necessário transformá-lo por completo, reformando sua estrutura física e fiscalizando suas apropriações cotidianas, visando reprimir usos considerados insurgentes. No entanto, apesar de defendida como "necessária", a reforma da praça só foi oficialmente cogitada pela administração municipal de São Paulo em meados dos anos 2000. Sua complexa construção política, bem como sua inserção em um escopo de

${ }^{8}$ Aqui, me utilizo da terminologia proposta por Magnani (2002). 
intervenções urbanísticas voltadas ao centro de São Paulo, dependeu da articulação de uma série de agentes.

No início dos anos 1990, após um longo período em que o centro de São Paulo praticamente não recebeu recursos públicos para a realização de intervenções urbanísticas (o que também contribuiu para que a região passasse a ser representada como "degradada"), ele voltaria às pautas da administração municipal. Isso em grande medida se deve à formação da Associação Viva o Centro, organização composta por diversos segmentos da "sociedade civil", com protagonismo econômico e diretivo de agentes ligados a instituições financeiras instaladas no centro, especialmente o Banco de Boston (FRÚGOLI JR., 2000) ${ }^{9}$. Buscando se colocar publicamente como organização da sociedade civil com o objetivo de propor e discutir "soluções" para a situação de degradação da região central, a associação contava com a assessoria técnica de arquitetos e urbanistas, ao mesmo tempo que buscava o apoio de moradores, roprietários e empresas da região a partir de suas Ações Locais.

Nesse contexto, a associação se torna um ator político com relativa interlocução com o poder público. Anos mais tarde a Prefeitura de São Paulo, sob a gestão de Paulo Maluf (PPB), institui a criação do ProCentro, programa que tinha a representação de órgãos e agentes públicos, como a Emurb, as forças policiais (Polícia Militar e Guarda Civil Metropolitana) e a Subprefeitura da Sé, e também da Associação Viva o Centro. Pouco tempo depois, em 1997 (já sob a gestão de Celso Pitta, também do PPB), foi implementada a Operação Urbana Centro. Nesse contexto inicial, alguns projetos de reforma da Praça Roosevelt chegaram a ser propostos, porém inicialmente outros espaços acabaram sendo privilegiados como palco de intervenções requalificadoras como a Praça da Sé e a Praça do Patriarca.

Já no início dos anos 2000 a praça Roosevelt voltaria a figurar como um pedaço de cultura em São Paulo, o que se deve especialmente à atuação de grupos teatrais independentes que instalaram salas nos seus entornos - como o Cemitério de Automóveis, o Parlapatões, patifes e paspalhões e, principalmente, o Satyros. Na medida em que esses grupos teatrais "redescobriam" a praça Roosevelt, território até então tido como degradado, alguns moradores dos

\footnotetext{
${ }^{9} \mathrm{O}$ poder público já havia tentado intervir na região central através da Operação Urbana Anhangabaú, em 1990 (durante a gestão de Luiza Erundina, do PT), e de algumas intervenções pontuais promovidas pelo governo do estado ainda nos anos 1980. Porém a formação da Associação Viva o Centro, bem como as avaliações de insucesso dessas intervenções anteriores, em grande medida se justificavam pela narrativa de que tais iniciativas deveriam ser conduzidas a partir de uma maior articulação junto ao terceiro setor, e não do protagonismo do poder público.
} 
entornos da praça passavam a se queixar do barulho produzidos pelos frequentadores dessas salas teatrais e de seus bares. Ao mesmo tempo, aquela movimentação teatral voltava a atrair um público elitizado. Em meio a esses conflitos, presencia-se o início de um processo de gentrificação (SMITH, 2007) da região. E é exatamente nesse contexto que a Prefeitura de São Paulo volta a discutir a inserção da reforma da praça nas intervenções dirigidas à requalificação da região central.

Em meados dos anos 2000, a Prefeitura de São Paulo assina um acordo com o Banco Interamericano de Desenvolvimento para financiamento de obras de requalificação urbana no centro histórico da cidade. Esse é outro elemento muito importante para que a reforma da praça Roosevelt fosse inserida nesse escopo mais amplo de intervenções. A assinatura desse acordo com o BID pontuou um deslocamento com relação às prioridades públicas da implementação de intervenções inseridas no escopo do ProCentro, com maior ênfase em intervenções produtoras de "requalificação urbana" e menor ênfase em políticas voltadas à habitação popular e ao transporte, por exemplo (KARA JOSÉ, 2010).

Nesse contexto, muitos projetos foram propostos para a reforma da praça. $\mathrm{Na}$ verdade o projeto que foi aprovado nunca foi integralmente executado, na medida em que os muitos agentes políticos envolvidos na execução da reforma da praça negociavam ferozmente a presença e a disposição dos equipamentos urbanos que nela estariam disponíveis, independentemente do que estava previsto no plano original. Passados todos esses trâmites, as obras se iniciaram em 2010, e duraram até 2012. Os custos totais chegaram a R \$ 55 milhões, muito a mais do que o valor inicialmente divulgado pela prefeitura (em torno de R\$ 37 milhões).

A praça entregue à população em janeiro de 2012 era uma grande área plana e concretada, equipada com duas bases policiais, uma base da Polícia Militar e outra da Guarda Civil Metropolitana (além de câmeras de vigilância e iluminação), além de um "cachorródromo", um parquinho infantil e uma área destinada à instalação de estabelecimentos comerciais (como "cafés" e floriculturas) - mas com pouquíssimas áreas verdes, sem tetos, banheiros públicos, bebedouros ou mesmo o "teatro de arena", equipamento reivindicado por agentes ligados aos grupos teatrais da região (YAMASHITA, 2013). Apesar de terem relativo protagonismo nesse processo de desbravamento da praça Roosevelt, os grupos teatrais independentes acabaram não figurando como agentes políticos influentes na idealização e na execução da reforma da praça. Os interesses de moradores e proprietários da 
região, e também da gestão pública e das forças policiais, ao que parece, tiveram mais peso nesse processo.

\section{0 contexto pós-reabertura}

A reforma da praça Roosevelt foi fortemente motivadas por uma tentativa de estabelecimento de um ordenamento restritivo de seus usos cotidianos. A praça entregue à população refletia essa tentativa: uma área quase completamente concretada, plana, bem iluminada e bem policiada, com policiais militares, guardas civis, câmeras de vigilância. Porém, suas apropriações práticas atualmente desvelam uma pluralidade de ruídos, questionamentos e mesmo limites de tal projeto ordenador. O cenário noturno da praça é frequentado por uma série de atores: Skatistas, ciclistas, estudantes, jovens recém-saídos de seus trabalhos, o pessoal do teatro, a molecada de periferia, os movimentos culturais e sociais, os moradores de rua, os vendedores ambulantes, entre outros. Ao se apropriarem daquele espaço, esses atores "fazem cidade", desestabilizando os pontos de vistas planificadores e totalizantes de agentes engajados na gestão do urbano. Mas onde alguns veem livre apropriação do espaço, outros veem mau uso, vandalismo, uso de drogas, barulho e perturbação da ordem.

Se, de um ponto de vista do perfil social de seus habitantes e usuários, a gentrificação está ligada a uma elitização, através da instalação de estabelecimentos comerciais voltados a um público de alto poder aquisitivo e da securitização ostensiva, de um ponto de vista político nem sempre esse projeto se concretiza sem conflitos. No caso da praça Roosevelt, apesar dos estabelecimentos comerciais voltados a um público de alta renda e do policiamento massivo, podemos dizer que ela está longe de ser um espaço exclusivamente frequentado pelas elites. Justamente por ser uma espécie de "centralidade cultural/de lazer" na cidade, ela atrai um público bastante amplo e heterogêneo. Tais apropriações cotidianas desse espaço mobilizam diferentes projetos de gestão, em torno dos quais se constituem grupos e redes políticas, que estabelecem alianças e disputas uns com os outros.

Logo após a reabertura da praça Roosevelt, no início de 2013, o primeiro conflito político nesse espaço disputado se faria presente. $O$ conflito foi motivado pela publicização de um vídeo na internet, que filmava uma ação repressiva de um guarda civil a paisana contra um grupo de skatistas que praticava manobras na praça. Ironicamente, a praça plana e cimentada, projetada para ser uma espécie de "enclave fortificado público" era também 
muito boa para a prática do skate ${ }^{10}$. A publicização desse vídeo gerou diferentes reações. Houve os que se posicionaram contra a intervenção e a favor dos skatistas, defendendo que a criminalização da prática atentava contra a livre apropriação dos espaços públicos. Outros, por sua vez, se posicionaram a favor de uma regulação restritiva e, no limite, de uma proibição da prática do skate no local, alegando que aquela forma de uso do espaço era imprópria. $\mathrm{O}$ jornalista da Revista Veja, Reinaldo Azevedo, por exemplo, chegou a publicar um artigo intitulado "Fascistas de skate", onde argumentava em prol da proibição da prática na praça Roosevelt (MACHADO, 2014).

A saída adotada pelo prefeito recém-empossado Fernando Haddad (PT) foi a de incentivar a prática do skate na praça Roosevelt, inclusive mediante promoção de eventos públicos voltados ao skate na praça. Mas, ao lado do incentivo, veio a tentativa de regulação: Através de conversa entre representantes dos skatistas e das forças policiais (PM e GCM), mediadas pela prefeitura, estabeleceu-se um perímetro delimitado da praça onde o skate seria permitido. Essa parte foi equipada com obstáculos próprios para o skate, enquanto em outras partes foram instaladas placas sinalizando que "ali era proibido andar de skate" (MACHADO, 2014). Atualmente, no entanto, em quase qualquer noite na praça Roosevelt, é possível se ver skatistas andando e praticando manobras em outros espaços da praça além desse perímetro acordado em 2013. Muitas vezes pedestres mais desatentos chegam perto de se chocar contra os skatistas em rápido movimento. Os skatistas só não representam para esses pedestres desatentos um perigo maior do que o oferecido pelo também rápido e frequente deslocamento de viaturas da PM e da GCM, nos arredores e também dentro da praça. Durante meu trabalho de campo, foram muitas as vezes em que eu pude ver pessoas quase sendo atropeladas por viaturas circulando em alta velocidade.

Nos anos seguintes, a praça Roosevelt se tornaria não apenas um pedaço de cultura, mas também um pedaço de "resistência cultural". Isso em forte medida se deve à atuação do Slam Resistência, coletivo cultural atuante na praça desde 2014. Vinculado à cena dos slams de poesia marginal, o coletivo realiza intervenções poéticas mensais na praça. Esses eventos/intervenções são abertos à participação do público. Mais que uma intervenção poética, o slam é também uma competição entre poetas, uma espécie de "batalha de poesias". Estética e discursivamente, os slams de poesia são próximos de outras

\footnotetext{
${ }^{10}$ Segundo Machado (2014), a praça Roosevelt mesmo antes de sua reforma já era um lugar apropriado por skatistas, sendo considerada um dos locais de nascimento da prática em São Paulo.
} 
manifestações culturais contemporâneas vinculadas à juventude das periferias em São Paulo, como o Hip Hop ${ }^{11}$ e a literatura marginal ${ }^{12}$. As temáticas abordadas por poetas que frequentam esses slams em suas poesias dialogam com temas tratados no Rap ou em outras modalidades de literatura e poesia marginal, como o racismo, a exclusão social e o cotidiano das periferias paulistas. Ao mesmo tempo que se vinculam a esse conjunto mais amplo de uma "cultura de rua" (PEREIRA, 2018), os slams indicam um deslocamento mais contemporâneo dessas mobilizações, que passam a ser mais pautadas pela realização de intervenções culturais em espaços públicos ${ }^{13}$. Nesse cenário atual, outras temáticas são mobilizadas - não de forma inconteste - em articulação a esse escopo estético/discursivo, como a desigualdade de gênero e a heteronormatividade.

Em certo sentido, os slams de poesia atuam como espécie de plataforma de publicização de experiências cotidianas, estabelecendo um vínculo discursivo entre o subjetivo e o político. Através dos slams, muitos jovens poetas, que se identificam como vindos das periferias, negros, mulheres, homossexuais, relatam suas experiências e seus pensamentos sobre a vida e sobre o mundo. Possivelmente é aí que reside o grande potencial politizador de tais intervenções poéticas, ainda mais quando elas ocupam um espaço como a praça Roosevelt, uma praça em uma região nobre do centro de São Paulo. Ainda que muitas das pessoas frequentadoras do Slam Resistência fossem também frequentadores de outros slams, haviam também aqueles que eram frequentadores da praça, alguns deles até mesmo moradores dos arredores. Pessoas não tão habituadas a lidar de perto com as alteridades sociais, e que, em outras ocasiões, dificilmente teriam algum contato com esse tipo de discurso - ao menos não em condição de receptividade.

Assim como a prática do skate, a realização do Slam Resistência na praça Roosevelt mobiliza dissensos, entre aqueles que veem nele uma mobilização política válida e legítima e os que o consideram como evento produtor de

\footnotetext{
11Para mais sobre o Hip Hop e o Rap em São Paulo, ver Bertelli (2017), Oliveira (2015) e Teperman (2011; 2015).

12 Para mais sobre a literatura e a poesia marginal, ver Nascimento (2006; 2011) e Silva (2013).

${ }^{13}$ Essa questão é discutida por Aderaldo, a partir de uma análise sobre a atuação de um coletivo audiovisual, o Cinescadão (ADERALDO, 2013). Se de um ponto de vista gestionário, podemos apontar, como bem salienta Rizek (2013), a cultura como um dispositivo contemporâneo de gestão da pobreza, Aderaldo (2013) destaca que os sujeitos aos quais tais políticas culturais públicas e privadas são dirigidas também se apropriam desses instrumentos gestionários, como, editais públicos, cursos e vínculos profissionais, para produzir intervenções culturais independentes e politizadas.
} 
"perturbação da ordem pública", sendo por isso passível de criminalização e repressão. Em março de 2017, por exemplo, o slam chegou a ser interrompido por guardas civis metropolitanos. Os guardas exigiam que a intervenção fosse encerrada porque os moradores dos prédios dos arredores da praça reclamavam do excesso de barulho. Até então, o coletivo nunca havia encontrado qualquer resistência das forças policiais para realizar suas intervenções mensais na praça.

Os organizadores do slam argumentaram que a "lei do artista de rua" 14 lhes dava respaldo legal para a realização daquela intervenção. Iniciou-se uma negociação entre guardas e poetas, em meio às vaias de parte do público presente. Os organizadores do coletivo pediam calma ao público. Depois de alguns minutos de negociação, ficou acordado que o slam seguiria até as 22 horas, horário limite estipulado pelo Programa do Silêncio Urbano para a emissão de ruídos considerados altos. A intervenção prosseguiu até aproximadamente as 22:30, sendo encerrada de forma prematura. Nesse momento já havia um cordão de policiais militares formado acima das escadarias onde é realizado o slam, mas eles não chegaram a evacuar a praça.

As reclamações dos moradores dos arredores da praça com relação ao barulho produzido pelas intervenções do Slam Resistência certamente não se iniciaram em 2017. Mas, até então, elas não se concretizavam em intervenções policiais visando o impedimento da realização da intervenção. Segundo Gustavo LeGusta, poeta e um dos fundadores do Slam Resistência - e, na época desse acontecimento, um de seus organizadores ${ }^{15}$-, essa mudança pode ser atribuída a dois elementos. Primeiro, não se pode ignorar que os slams promovidos pelo coletivo passaram a ter uma visibilidade significativa, o que em grande medida se deve à mobilização de mídias digitais, como o facebook e o youtube, para a divulgação de performances poéticas ocorridas nessas intervenções. Alguns desses vídeos chegaram a mais de um milhão de visualizações. Isso não apenas contribuiu para uma maior visibilidade da atuação do coletivo (e também da cena dos slams de poesia de forma mais geral) como também contribuiu diretamente para um significativo aumento do público presente nos slams ${ }^{16}$. Portanto, efetivamente, a realização dessas intervenções passou a produzir mais barulho, o que é reconhecido por LeGusta.

\footnotetext{
${ }^{14} \mathrm{~A}$ "lei do artista de rua" é a Lei n ${ }^{0} 15.776$, de 29 de maio de 2013, posteriormente regulamentada através do Decreto n ${ }^{\circ} 55.140$, de 23 de maio de 2014.

${ }^{15}$ Entrevista realizada pelo pesquisador no dia 2 de junho de 2017.

${ }^{16} \mathrm{Eu}$ pude constatar esse aumento durante a realização dessa pesquisa: Se, em meados de 2016, o público presente nesses slams era de pouco mais de 100 pessoas, no início de 2017 ele já chegava a
} 
Por outro lado, a mudança de postura da administração municipal de lidar com as questões envolvidas é também um elemento relevante. O ano de 2017 marca o fim da gestão de Fernando Haddad e a posse de João Dória (PSDB) na Prefeitura Municipal. A partir da gestão de um perfeito de perfil político abertamente mais conservador, as reclamações dos moradores dos arredores da praça passaram a ter maior interlocução junto ao poder público. Os efeitos práticos dessa maior interlocução foram imediatos: a situação acima descrita ocorreu no primeiro slam após a posse do novo prefeito. Poucos dias depois, os organizadores do Slam Resistência foram convocados para uma reunião com representantes da Secretaria de Segurança Pública, onde foi oficialmente determinado que os slams mensais organizados pelo coletivo não durariam até depois das 22 horas, não utilizariam equipamentos de som, como caixas de som ou amplificadores, e não promoveriam intervenções musicais, como a apresentação de bandas ou músicos.

No mesmo ano de 2017, o Slam Resistência havia sido, pela primeira vez, aprovado como coletivo participante da programação da Virada Cultural evento cultural anual realizado pela Prefeitura de São Paulo. A apresentação do Slam Resistência ocorreria no mesmo lugar onde suas intervenções geralmente eram conduzidas, na praça Roosevelt. A diferença era que dessa vez, supostamente, haveria um palco, com equipamentos de som, além do cachê previsto no edital de seleção ( $R$ \$ 3.000). Porém, na hora marcada para o início da apresentação, o palco ainda não havia sido devidamente montado e equipado, havendo no espaço apenas um modesto toldo branco sem microfones, alto-falantes, mesa ou técnicos de som.

A intervenção se iniciou mesmo assim, sendo, no entanto, interrompida algum tempo depois por uma funcionária da organização da Virada Cultural. Ela alegou que "havia dado um erro na papelada da inscrição do slam", e que por isso a apresentação deles não constava mais na programação oficial do evento. E, para piorar a situação, ela pediu para que aquela intervenção fosse interrompida porque os moradores dos arredores estariam, novamente, reclamando do barulho. Dessa vez não houve negociação. Os organizadores do slam negaram os pedidos, seguiram sua intervenção e manifestaram em mais de uma oportunidade seu repúdio à organização da Virada Cultural e ao novo prefeito. Dessa vez não houve a presença de policiais ameaçando evacuar a praça a bombas de gás e balas de borracha. Ao mesmo tempo, pareceu mais

cerca de 500 pessoas. 
evidente que coletivos culturais como o Slam Resistência teriam uma difícil interlocução com a prefeitura a partir dali.

\section{A gestão da praça Roosevelt em disputa}

“(...) a praça está hoje totalmente degradada, com pichações, tendo se transformado em local de consumo de drogas e vandalismos de toda espécie. Sem horário de fechamento, o espaço é motivo de transtorno para os moradores do entorno que não têm mais sossego sequer para ter uma noite de sono tranquila. Transformando a praça em parque, com a ocupação do espaço pelo poder público afim de de conservar e fiscalizar o uso adequado, certamente haverá menos gastos em longo prazo, garantia de lazer a todos os cidadãos que sentir-se-ão seguros de ali frequentar, além de propiciar melhoria na qualidade de vida aos moradores do entorno ao permitir-lhes o sossego noturno assegurado pelo Programa de Silêncio Urbano (PSIU)"17.

“Queremos para a Praça Roosevelt um ambiente onde todxs possam exercer suas liberdades sem atrapalhar o próximo. Defendemos as várias formas de cultura, lazer, de ser e de existir. Livres de raça, sexo, cor, status social. Acreditamos na coexistência harmoniosa e na capacidade de resolver conflitos de forma saudável e respeitosa, bem como no trabalho conjunto e em abordagens educativas.

Entendemos que os problemas existentes e devem ser resolvidos baseados em dois princípios gerais: no diálogo democrático, amplo e respeitoso entre todxs; e na manutenção do caráter público e igualmente democrático da praça. Um espaço livre, sem grades, sem preconceitos"18.

Depois de reformada e reaberta, a praça Roosevelt passou a ser um espaço disputado por uma pluralidade de agentes e de projetos políticos. Em meio às suas apropriações cotidianas, alguns defendiam que sua segurança deveria ser reforçada, enquanto outros entendem que a regulação dessas formas

\footnotetext{
${ }^{17 T}$ Texto de justificativa ao Projeto de Lei 0421 de 2016, que propõe o cercamento da Praça Roosevelt e a sua transformação em parque público. Texto de autoria do propositor do projeto de lei, o vereador Eliseu Gabriel. Fonte: Diário Oficial da Cidade de São Paulo, edição de 11 de agosto de 2016.

18 Excerto de manifesto redigido pelo Comitê Praça Roosevelt de Todxs! durante o Carnaval de 2017. O documento na íntegra pode ser acessado no link https://docs.google.com/document/d/151PH0EPb6gUTbyi7VBI_axFoL2k-

C91T_3ciN6ZBfd0/edit. (Último acesso: 09/10/2020).
} 
divergentes de uso devem ser produzidas a partir do diálogo democrático, e não do policiamento e da securitização ostensiva.

A esse até aqui já bastante conflitivo cenário, adiciona-se um elemento ainda não citado mas muito relevante. No ano de 2016, o vereador Eliseu Gabriel (PSB) encaminha à Câmara dos Vereadores de São Paulo o Projeto de Lei $\mathrm{n}^{0}$ 0421/2016, que propunha que a praça Roosevelt fosse cercada e transformada em parque público, com restrição do acesso do público e horários estabelecidos de funcionamento. Segundo justificativa apresentada pelo vereador, isso possibilitaria ao poder público maior conservação e maior fiscalização do local, garantindo a melhoria da qualidade de vida dos moradores dos entornos e benefícios aos cidadãos em geral, que passariam a se sentir seguros para frequentá-la. Se a própria reforma da praça, concluída apenas quatro anos antes, também se propunha a "melhorar a qualidade urbana" do local, o encaminhamento desse Projeto de Lei sugere que, para alguns, ela não teria alcançado esse fim. Propunha-se, dessa forma, uma extensão do projeto securitizador iniciado pela reforma.

A proposição desse projeto foi em grande medida encabeçada pela AMACON, a Associação de Moradores e Amigos da Consolação e Adjacências. Composta majoritariamente por moradores, comerciantes, proprietários e representantes de edifícios da região da Consolação, a AMACON foi formada no ano de 2014, e é presidida por Marta Lília Porta - atualmente presidente também do CONSEG Consolação ${ }^{19}$. Trata-se de um grupo político formado em torno da defesa de um modelo securitário de gestão de espaços públicos, e que propunha também intervir na gestão da praça Roosevelt. Grupo este que visa, sobretudo, atuar em proximidade com o poder público e com as forças policiais para intervir no policiamento da região.

Esse Projeto de Lei, no entanto, saiu de tramitação em 2017. Enquanto o projeto de cercamento era formalmente deixado de lado, outras formas de securitização dos usos da praça seriam implementadas. Além da já citada intervenção da Guarda Civil Metropolitana tentando impedir a realização do Slam Resistência, nesse mesmo ano a Prefeitura de São Paulo anuncia que não

\footnotetext{
${ }^{19}$ Informações extraídas da página da associação no facebook (link: https://www.facebook.com/AMACONsp/ - Último acesso: 09/10/2020). Marta Lília Porta é antiga integrante da Ação Local Praça Roosevelt, Ação Local ligada à Associação Viva o Centro atuante na região, e um dos grupos que participou ativamente dos debates em torno da reforma da praça em 2010. Para mais sobre a Associação Viva o Centro, ver Frúgoli Jr (2000). Sobre os CONSEG's, eles são instrumentos de segurança comunitária instituídos nos anos 1980. Em algumas regiões da cidade, sobretudo em regiões mais elitizadas, os CONSEG's locais são uma instância importante para a produção de diretrizes de policiamento e até mesmo de gestão urbana.
} 
seriam mais permitidas aglomerações festivas na praça durante o feriado do Carnaval. Desde sua reabertura, a praça se tornou um dos muitos pontos da cidade que recebiam tais aglomerações. Naquele ano no entanto, não apenas elas estavam proibidas como havia ameaça de evacuação por parte da Tropa de Choque da Polícia Militar em caso de descumprimento dessa determinação.

Diante disso, um coletivo político intitulado Comitê Gestor Praça Roosevelt de Todxs! publica nas redes sociais um manifesto contrário à atuação da administração municipal e à implementação de um modelo de gestão dos espaços públicos repressivo e antidemocrático. Segundo o coletivo, os problemas relativos aos usos do espaço deveriam ser discutidos através do diálogo e da convivência entre as diferenças, e não da repressão e da regulação restritiva. Se propondo como um comitê de gestão participativa ${ }^{20}$ da praça, o coletivo formado em 2016 se coloca como grupo opositor ao projeto de gestão da praça Roosevelt encabeçado pela AMACON, e vem buscando sua formalização junto ao poder público desde 2017 - até o momento, sem sucesso. Curiosamente, um dos vereadores que manifestaram apoio à formalização do coletivo é Eliseu Gabriel, o mesmo que redigiu o Projeto de Lei propondo o cercamento da praça em 201621. Depois de muitas conversas com agentes ligados ao coletivo, o vereador passaria a defendê-lo, posição que parece mais condizente com seu perfil político. Apesar disso, a AMACON ainda desfruta de maior interlocução com o poder público e com os agentes policiais atuantes na praça, sendo mais capaz de intervir de forma concreta na regulação de seus usos cotidianos.

\footnotetext{
${ }^{20} \mathrm{~A}$ gestão participativa de espaços públicos é instrumento implementado pela lei municipal $\mathrm{n}^{\circ}$ 16.212 de 2015, de autoria do então vereador Nabil Bonduki (arquiteto e urbanista da FAU-USP) durante a gestão de Fernando Haddad. Ela prevê a formação de comitês gestores, compostos por moradores e usuários, incumbidos de gerir esses espaços públicos de forma participativa. Em tese, esse instrumento urbanístico ainda existe em termos legais, mas ele representa uma clara ruptura com relação às gestões seguintes, de prefeitos do PSDB (de perfil mais conservador), e por isso não vem sendo utilizado.
}

${ }^{21}$ Além do vereador Eliseu Gabriel, sinalizaram apoio para a formalização do Comitê Gestor Praça Roosevelt de Todxs! os vereadores José Police Neto (PSD) e Toninho Vespoli (PSOL). Os três vereadores assinaram a carta de solicitação da formalização do Comitê Gestor, entregue ao então subprefeito da Sé, Eduardo Odloak, no ano de 2018. O coletivo chegou a divulgar em sua página no facebook uma fotografia dessa carta, como estratégia para cobrar uma resposta da administração municipal com relação à solicitação de formalização (a imagem pode ser acessada no link

https://www.facebook.com/rooseveltdetodxs/photos/a.1685148371800593.1073741828.16851430 35134460/1957188457929915/?type=3\&theater - Último acesso: $-9 / 10 / 2020$ ). 


\section{Intervenções culturais e gestão participativa: cidades diferentes, "direitos à cidade" distintos}

Se a discussão lefebvriana sobre o "direito à cidade" (LEFÉBVRE, 2001) é um referente importante para pensarmos dimensões políticas dos usos cotidianos da cidade, nem todos os agentes aqui envolvidos pensam as relações entre cidade e direito da mesma forma. Enquanto alguns a associam à defesa de modelos alternativos de gestão de espaços públicos, como a gestão participativa, outros a associam muito mais à ocupação desses espaços públicos, o que não é a mesma coisa.

Essas duas formas diferentes de se conceber o potencial politizador das apropriações cotidianas de espaços públicos se distinguem precisamente pela forma como pensam a potência política da convivência entre as diferenças. Enquanto a lógica por trás da defesa da gestão participativa de espaços públicos, muito inspirada em uma narrativa política de esquerda/progressista, defende o diálogo enquanto estratégia de produção de consenso entre pontos de vista divergentes, a lógica por trás da ocupação de espaços públicos através de intervenções urbanas propõe o dissenso como linguagem de expressão política.

Em uma cidade socialmente segregada, como São Paulo, a simples presença de determinadas pessoas em certos tipos de espaço produz dissensos. Pereira (2017), por exemplo, menciona o exemplo dos rolezinhos. Embora se tratem de conflitos ocorridos em espaços de consumo privados, e não em espaços públicos, os rolezinhos são um interessante mote para pensarmos de que forma a simples presença de jovens de origem periférica é um elemento que mobiliza dissensos em torno da gestão dos usos de espaços públicos, que mobiliza um chamado público por segurança e repressão. Mas a lógica de ocupação dos espaços, diferente da lógica do diálogo, não pressupõe a produção de um entendimento, e sim a produção de um ruído. Nesse sentido, se expressar é também confrontar o cenário e os presentes, e exigir o direito de falar sobre si mesmo através da recusa de mediações discursivas ou simbólicas. Essa postura desafiadora desestabiliza projetos ordenadores de gestores públicos e de agentes policiais, mas também desafia certas narrativas políticas mobilizadas pela "esquerda progressista".

Aqui, me volto novamente às intervenções poéticas promovidas pelo Slam Resistência. Nessas intervenções, era bastante frequente que poetas mobilizassem em suas performances duras críticas à esquerda política e 
também aos pesquisadores acadêmicos - especialmente aqueles que faziam pesquisas em periferias. Muitos desses discursos críticos gravitavam em torno de um eixo comum de conteúdos: tanto a esquerda quanto os acadêmicos se dizem "aliados" dos pretos, dos pobres e dos periféricos, mas ao se afirmarem como "representantes" destes, ambos reatualizariam relações de poder entre pretos e brancos, entre pobres e ricos - entre pesquisados e pesquisadores, entre objetos de políticas públicas e seus formuladores. Haveria, portanto, uma alteridade frente esses agentes, que pode ser construída e estabelecida de muitas formas - desde o quase lúdico ato de zombar de um "otário" ao menos bem humorado ato de atacar agressivamente um inimigo.

Á primeira vista, essa crítica, que equipara pesquisadores acadêmicos a militantes da esquerda política pode parecer um simples reducionismo. Mas ela ganha algum sentido quando nos atentamos para o fato de que a consolidação dos estudos urbanos enquanto campo de pesquisas no Brasil teve ampla relação com a produção de estudos sobre as "periferias urbanas", em um contexto de luta por redemocratização política (entre os anos 1970 e 1980)22. O paradigma da redemocratização estava fortemente presente na forma como esses estudos viam as periferias (MENDOZA, 2000). Nesse contexto, assim como as esquerdas políticas, os acadêmicos depositariam nessas populações a esperança da redemocratização do Brasil. Porém, a consolidação do regime democrático no Brasil anos mais tarde coincidiu com uma despolitização da gestão da pobreza, que se aproximaria da filantropia e da tecnificação (FELTRAN, 2007, 2014). E, mais do que isso, atualmente as periferias são lidas no debate público não a partir da esperança por democracia, mas sim como evidência dos limites da redemocratização. Nesse cenário, faz mais sentido que a democracia seja vista como "promessa não cumprida" nas periferias, e que a culpa por esse fracasso seja partilhada entre os intelectuais e as esquerdas.

Formalmente, os organizadores do Slam Resistência mantém certo diálogo com o Comitê Gestor Praça Roosevelt de Todxs!, sendo inclusive um dos muitos agentes políticos que assinaram o já referido manifesto publicizado no carnaval de 2017. Mas, enquanto intervenção cultural, os slams de poesia atuam como plataforma para a publicização de uma pluralidade de discursos políticos, não necessariamente mediados pelas articulações políticas de seus organizadores. Nos slams mensais na praça Roosevelt, muitos poetas autodeclarados pretos, periféricos, mulheres, homossexuais, transgênero,

22 Aqui me refiro a trabalhos produzidos tanto na área da antropologia (CALDEIRA, 1984; ZALUAR, 1994; DURHAM, 2004) quanto na área da sociologia (PAOLI, 1995; SADER, 1988). 
mobilizam poesias e performances poéticas para ocupar aquele espaço, para expressar suas experiências subjetivas, publicizá-las e se fazer presente na cidade. O próprio fato de a praça Roosevelt ser um espaço localizado em uma região nobre do centro da cidade não deixa de ser simbólico nesse sentido: nas noites de slam na praça Roosevelt, a periferia (literalmente) ocupa o centro. Ocupação não implica em diálogo: implica em se fazer ouvir, não necessariamente em se fazer entender.

Há aqui uma associação entre subalternidade e invisibilidade, e também entre visibilidade e empoderamento. Se fazer presente na cidade, de certa forma, é reivindicar a voz que é negada pela política institucional e pela "cultura hegemônica", que fala das periferias e de seus habitantes de um ponto de vista "de fora". E, acima de tudo, é reivindicar o direito de falar por si mesmo, independentemente da mediação de outros agentes que, ao pretenderem "falar pelos subalternos", reafirmam essa lógica desigual de silenciamento. Contra a violência epistêmica (SAID, 1990; SPIVAK, 2010) dos discursos oficiais, mobiliza-se o "lugar de fala" enquanto questionamento à própria produção da autoridade discursiva, política e científica.

\section{Considerações finais}

A produção prática dos espaços públicos envolve uma multiplicidade de elementos, e mobiliza uma pluralidade de agentes, de redes pessoais e de instituições políticas ou econômicas. A praça Roosevelt nos fornece um exemplo específico e, ao mesmo tempo, elucidativo, para pensarmos as articulações entre a gestão de territórios urbanos e a produção de intervenções urbanas gentrificadoras. Um exemplo que nos convida a pensar de forma mais detida sobre as interfaces entre a acumulação do capital e a produção de ordenamentos de territórios e de fluxos, e também sobre os dissensos e conflitos que se estabelecem em sua produção. Esses projetos ordenadores são constantemente desafiados no plano do cotidiano. O chamado "recorte policial" do mundo sensível (RANCIÉRE, 2005), a partilha do sensível produzida pelos agentes e dispositivos gestionários, é cotidianamente desafiado a partir de apropriações dissensuosas dos espaços urbanos.

Se, em um plano normativo, a controvérsia política aqui exposta pode ser vista como conflito entre dois modelos/projetos de gestão de espaços públicos, o plano da política das práticas revela que, em ambos os "lados" aqui descritos, há construção de articulações e de conflitos, de estratégias, apropriações e rupturas. Não se pode, portanto, sob essa perspectiva, falar em um conflito 
entre "dois lados". Por um lado, a AMACON parece representar uma extensão drástica de um projeto de ordenamento restritivo já presente na própria realização da reforma da praça Roosevelt, mas essa extensão propõe rupturas com relação a esse projeto estatal anterior a partir de uma constatação de suas lacunas e de seus insucessos. Da mesma forma, o coletivo Praça Roosevelt de Todxs!, que extrai sua legitimidade política não de uma interlocução com o poder público mas sim de articulações com outros atores políticos, defende um projeto de gestão do espaço que se defende como democrático mas que ainda assim se projeta enquanto produção de um recorte policial. Recorte este que também é questionado em meio às apropriações práticas da praça.

Essa interface entre coletivos de gestão participativa de espaços públicos e coletivos culturais autodeclarados periféricos é muito interessante para pensarmos a polissemia do "direito à cidade" na contemporaneidade. As discussões em torno da gestão participativa enquanto modelo alternativo de gestão de espaços públicos não estão situadas no mesmo campo político do que a atuação de coletivos culturais e as pautas identitárias por eles mobilizadas. Da mesma forma como a luta de movimentos por moradia no centro da cidade, por exemplo, parecem se inserir em um campo diferente desses dois anteriores. Há diferenças significativas entre ocupar o centro para produzir intervenções culturais e para reivindicar moradia popular. Isso não significa que esses diferentes campos de luta política não possam produzir articulações uns com os outros, mas tais articulações não são dadas, elas devem ser construídas na prática através de articulações entre agentes e entre grupos políticos atuantes em cada um deles. Há muitos direitos à cidade em disputa no mundo urbano contemporâneo. Eles propõem uma multiplicidade de rupturas frente a produção de ordenamentos urbanos, da resistência à tentativa de produção de novos ordenamentos - que serão, novamente, objeto de disputas e de resistências cotidianas. Essa questão não é apenas teórica, ela produz efeitos práticos para a produção de pesquisas nas cidades, sobretudo de pesquisas etnográficas.

Durante a realização dessa pesquisa, o próprio diálogo com o campo em muitos momentos se configurou como um diálogo dissensuoso. Se considerarmos que a pesquisa etnográfica aposta na interação interssubjetiva como instrumento potente de produção de conhecimento, devemos considerar também que nós, pesquisadores, não somos os únicos capazes de estabelecer ou de negar essa interssubjetividade. Porém, eu acredito que a negação do diálogo também é uma forma de diálogo (uma forma específica, é verdade). Foi a partir dessa forma de diálogo que muitos dos meus interlocutores me 
permitiram analisar essa crítica contemporânea à autoridade de fala acadêmica enquanto crítica à neutralidade do discurso científico. Críticas semelhantes já tiveram ressonância no campo acadêmico, nos debates pós-coloniais (ASAD, 1975; GILROY, 2001; HALL, 2003; SAID, 1990; SPIVAK, 2010) e até mesmo na chamada "antropologia pós-moderna" (CLIFFORD, 2011; CLIFFORD E MARCUS, 1986; FABIAN, 2013). Mas eu acredito que o contexto contemporâneo nos oferece um cenário diferente, onde essa crítica é formulada de fora da academia. Assim como a cidade, a academia é vista como um espaço de representação, um símbolo do privilégio das elites brancas mas também um território disputado pelos pretos e pobres - aqueles a quem o acesso a esses espaços teria sido historicamente negado.

\section{Referências}

ADERALD0, Guilhermo André.

(2013). Reinventando a "cidade": disputas simbólicas em torno da produção e exibição audiovisual de "coletivos culturais" em São Paulo. Dissertação de doutorado apresentada à Faculdade de Letras e Ciências Humanas da Universidade de São Paulo.

AGIER, Michel.

(2015). Do direito à cidade ao fazer-cidade. 0 antropólogo, a margem e o centro. Revista Mana. v. 21. n. 3. p. 483-498.

(2011). Antropologia da cidade - lugares, situações, movimentos. São Paulo, Editora Terceiro Nome.

ASAD, Talal.

(1975). Anthropology and the colonial encounter. London/Atlantic Highlands, Ithaca Press/Humanities Press.

BERTELLI, Giordano.

(2017). Errâncias racionais: A periferia, o RAP e a política. In: Giordano Bertelli e Gabriel Feltran (Orgs.); Vozes à Margem - Periferias, estética e política. São Carlos, Edufscar, p. 21-38.
CALDEIRA, Teresa.

(2000). Cidade de muros: crime, segregação e cidadania em São Paulo. São Paulo, Edusp/Editora 34.

(1984). A politica dos outros: o cotidiano dos moradores da periferia e o que pensam do poder e dos poderosos. São Paulo, Brasiliense.

CASTELLS, Manuel.

(1972). A questão urbana. Rio de Janeiro, Paz e Terra.

CERTEAU, Michel de.

(2009). A invenção do Cotidiano. Petrópolis, Vozes.

CLIFFORD, James.

(2011). A experiência etnográfica: Antropologia e literatura no séc. XX. Rio de Janeiro, Editora UFRJ.

CLIFFORD, James. MARCUS, George. (eds.). (1986). Writting culture: The poetics and the politics of ethnography. Berkeley/Los Angeles, The University of California Press. 
DAS, Veena. P00LE, Deborah.

(2008). El estado e sus márgenes. Etnografias comparadas. Cuadernos de Antropología Social, Buenos Aires. n. 27, p. 19-52.

DURHAM, Eunice.

(2004). A dinâmica da cultura - Ensaios de Antropologia. São Paulo, Cosac e Naify.

FABIAN, Johannes.

(2013). O tempo e o outro: como a antropologia estabelece seu objeto. Petrópolis, Vozes.

FELTRAN, Gabriel de Santis.

(2014). 0 valor dos pobres: a aposta no dinheiro como mediação para o conflito social contemporâneo. Caderno CRH, Salvador. v. 27, n. 72, p 495-512.

(2012). Governo que produz crime, crime que produz governo: 0 dispositivo de gestão do homicídio em São Paulo (1992-2011). Revista Brasileira de Segurança Pública, v. 6, n.2, p 232-55.

(2011). Fronteiras de tensão: política e violência nas periferias de São Paulo. São Paulo, Editora Unesp/Centro de Estudos da Metrópole.

(2010). Margens da política, fronteiras da violência: Uma ação coletiva das periferias de São Paulo. Revista Lua Nova, n. 79, p 201-233.

(2007). Vinte anos depois: A construção democrática brasileira vista da periferia de São Paulo. Revista Lua Nova, n. 72, p 83-114.

FOUCAULT, Michel.

(2009). Microfísica do poder. Rio de Janeiro, Edições Graal.

(2005). Em defesa da sociedade: curso no Collège de France (1975-1976). São Paulo, Martins Fontes.

(1988). A história da sexualidade vol. 1: A vontade de saber. Rio de Janeiro, Edições Graal.

(1987). Vigiar e punir: Nascimento da prisão. Petrópolis, Vozes.
FRÚGOLIJR, Heitor.

(2000). Centralidade em São Paulo: trajetórias, conflitos e negociações na metrópole. São Paulo, Cortez/Edusp.

(1999). A questão dos camelôs no contexto da revitalização do centro da metrópole de São Paulo. In: Maria Adélia Aparecida de Souza et al. (orgs.). Metrópole e globalização: conhecendo a cidade de São Paulo. São Paulo, CEDESP.

FRÚGOLI JR, Heitor. Spaggiari, Enrico. ADERALD0, Guilhermo (Orgs.).

(2019). Práticas, conflitos, espaços - Pesquisas em Antropologia da Cidade. Rio de Janeiro, Gramma.

FURTAD0, Celso.

(2009). Desenvolvimento e subdesenvolvimento. Rio de Janeiro, Centro Celso Furtado/Contraponto.

GILROY, Paul.

(2001). O Atlântico Negro. Modernidade e dupla consciência, São Paulo/Rio de Janeiro, Editora 34/Universidade Cândido Mendes - Centro de Estudos Afro-Asiáticos.

GORELICK, Adrian.

(2005). A produção da “cidade latinoamericana". Tempo Social - Revista de Sociologia da USP, v. 17, n.1, p. 111-33.

HALL, Stuart.

(2003). Da diáspora: Identidades e mediações culturais. Belo Horizonte, Editora UFMG.

HARVEY, David.

(1992). Condição Pós-Moderna. São Paulo, Edições Loyola.

HIRATA, Daniel.

(2018). Sobrevivendo na adversidade - Mercados e formas de vida. São Carlos, EDUFSCar.

KARA JOSÉ, Beatriz.

(2010). A popularização do centro de São Paulo: Um estudo das transformações ocorridas nos últimos 20 anos. Tese de Doutorado apresentada à Faculdade de Arquitetura e Urbanismo da Universidade de São Paulo. 
KOWARICK, Lúcio.

(1979). A espoliação urbana. São Paulo, Paz e Terra.

LEFÉBVRE, Henri.

(2001). O direito à cidade. São Paulo, Centauro.

(1991). The production of space. 0xford (UK)/Cambridge (USA), Blackwell.

MACHAD0, Giancarlo.

(2014). Praça Roosevelt: Sociabilidade e conflitos em um pedaço skatista da cidade de São Paulo. Perifèria - Revista de recerca e formació em antropologia, UAB, Barcelona, n. 19 , v. 1. p. 82-107.

MAGNANI, José Guilherme Cantor.

(2002). De perto e de dentro: notas para uma etnografia urbana. Revista Brasileira de Ciências Sociais, São Paulo, v. 17, n. 49. p. 1129.

MENDOZA, Edgard.

(2000). Sociologia da Antropologia Urbana no Brasil - A década de 70. Tese de doutorado apresentada ao Instituto de Filosofia e Ciências Humanas da Universidade Estadual de Campinas.

MISSE, Michel.

(2010). Crime, sujeito e sujeição criminal: Aspectos de uma contribuição analítica sobre a categoria "bandido". Lua Nova, São Paulo, n. 79, p 15-38.

NASCIMENTO, Érica Peçanha do.

(2011). É tudo nosso! Produção cultural na periferia paulistana. Tese de doutorado apresentada à Faculdade de Letras e Ciências Humanas da Universidade de São Paulo.

(2006). "Literatura marginal": Os escritores da periferia entram em cena. Dissertação de mestrado apresentada à Faculdade de Letras e Ciências Humanas da Universidade de São Paulo.

OLIVEIRA, Roberto Camargos de.

(2015). Rap e política: Percepções da vida social brasileira. São Paulo, Boitempo.
PALMA, Daniela.

(2010). A praça dos sentidos: Comunicação, imaginário social e espaço público. Tese de doutorado apresentada à Escola de Comunicação e Artes da Universidade de São Paulo.

PAOLI, Maria Celia.

(1995). Movimentos sociais no Brasil: em busca de um estatuto político. In: Michaella Hellmann. (org). Movimentos sociais e democracia no Brasil. São Paulo, Marco Zero/Ildesfes.

PARK, Robert E. BURGESS, Ernest W. (orgs.).

(1984). The city. Chicago/London, The University of Chiago Press.

PEREIRA, Alexandre Barbosa.

(2018). Um rolê pela cidade de riscos: Leituras da piXação em São Paulo. São Carlos, Edufscar.

(2017). Fluxos insurgentes em São Paulo: Os rolês que marcam a cidade. In: Giordano Bertelli e Gabriel Feltran (Orgs.). Vozes à Margem Periferias, estética e política. São Carlos, Edufscar, p. 171-190.

RANCIÉRE, Jacques.

(2005). A partilha do sensivel: Estética e política. São Paulo, Editora 34.

(1996). 0 dissenso. In: Adauto Novaes (org). $A$ crise da razão. São Paulo, Companhia das Letras, p. 367-383.

RIZEK, Cibele Saliba.

(2013). Práticas culturais e ações sociais: novas formas de gestão da pobreza. Caderno de debates: Juventude e Direitos na Cidade, Rio de Janeiro, p. 31-46.

ROLNIK, Raquel.

(1997). A cidade e a lei - Legislação, política urbana e territórios na cidade de São Paulo. São Paulo, Studio Nobel.

ROY, Ananya.

(2017). Cidades Faveladas: Repensando o urbanismo subalterno. Revista Eletrônica emetropolis, n. 31, ano 8. 
RUI, Taniele.

(2012). Corpos abjetos: etnografia em cenários de uso e comércio de crack. Tese de doutorado apresentada ao Instituto de Filosofia e Ciências Humanas da Universidade Estadual de Campinas.

SADER, Eder.

(1988). Quando novos personagens entram em cena: experiências e lutas dos trabalhadores na grande São Paulo. São Paulo, Paz e Terra.

SAID, Edward.

(1990). Orientalismo: O oriente como invenção do ocidente. São Paulo, Companhia das Letras.

SASSEN, Saskia.

(2007). A Sociology of Globalization. New York (US)/London (UK), W.W. Norton \& Company.

SILVA, Mário Augusto Medeiros da.

(2013). A descoberta do insólito: Literatura negra e literatura periférica no Brasil (19602000). Rio de Janeiro, Aeroplano.

SMITH, Neil.

(2007). Gentrificação, a fronteira e a reestruturação do espaço urbano. Espaço $e$ Tempo, USP. São Paulo. n. 21. p. 15-31.

SPIVAK, Gayatri.

(2010). Pode o subalterno falar? Belo Horizonte, Editora UFMG.
TEPERMAN, Ricardo.

(2015). Tem que ter suíngue: Batalhas de freestyle no metrô Santa Cruz. São Paulo, Claro Enigma.

(2011). Se liga no som: As transformações do rap no Brasil. Dissertação de mestrado apresentada à Faculdade de Letras e Ciências Humanas da Universidade de São Paulo.

ZALUAR, Alba.

(1984). A máquina e a revolta - as organizações populares e o significado da pobreza. São Paulo, Editora Brasiliense.

YAMASHITA, Kelly Yumi.

(2013). Praça Roosevelt, centro de São Paulo: intervenções urbanas e práticas culturais contemporâneas. Dissertação de mestrado apresentada ao Instituto de Arquitetura e Urbanismo da Universidade de São Paulo.

\section{Recebido em}

março de 2020

\section{Aprovado em}

outubro de 2020 